\title{
Correction to: Socially Assistive Robot for Providing Recommendations: Comparing a Humanoid Robot with a Mobile Application
}

\author{
Silvia Rossi ${ }^{1}\left[\right.$ [ $\cdot$ Mariacarla Staffa $^{2} \cdot$ Anna Tamburro $^{1}$ \\ Accepted: 10 July 2018 / Published online: 6 August 2018 \\ (c) Springer Nature B.V. 2018

\section{Correction to: \\ International Journal of Social Robotics (2018) \\ 10:265-278 \\ https://doi.org/10.1007/s12369-018-0469-4}

In the original publication, authors Silvia Rossi and Anna Tamburro's affiliations have been incorrectly reversed and should to be read correctly as "Department of Electrical Engineering and Information Technology".

Publisher's Note Springer Nature remains neutral with regard to jurisdictional claims in published maps and institutional affiliations.

The original article can be found online at https://doi.org/10.1007/s12 369-018-0469-4.

Silvia Rossi

silvia.rossi@unina.it

1 Department of Electrical Engineering and Information Technology, University of Naples Federico II, Naples, Italy

2 Department of Physics, University of Naples Federico II, Naples, Italy 